\title{
Atracurium versus vecuronium: a com- parison of recovery in outpatient arthroscopy
}

\begin{abstract}
Atracurium $0.5 \mathrm{mg}^{\circ} \mathrm{kg}^{-1}$ and vecuronium $0.1 \mathrm{mg} \cdot \mathrm{kg}^{-1}$ were compared as neuromuscular relaxants for outpatient arthroscopy of the knee under general anaesthesia. In 40 unpremedicated patients divided at random into no groups, anaesthesia was induced with methohexitone, atrucurium (Group $A$ ) or vecuronium (Group B), three per cent isofiurane prior to intubation and 0.9 per cent during maintenance with nitrous oxide 66 per cent in axygen. Neuromuscular function was recorded by a Datex Relaxograph ${ }^{\text {T }}$. Recovery was assessed by the time the patients look to open their eyes, to be able to answer five questions correctly, the time to recovery of ocular balance (Maddox Wing test) and by comparing pre-and postoperative performance of a paper and pencil test (the p-deletion test). Recovery tests showed no significant differences berween groups. After three hours all the patients were fit for discharge. The patiens were interviewed one month after the procedure. All were satisfied with their anaesthetic. "Full recovery" took 1.5 days with a range of I $h-7$ days. The only significant difference $(p<0.01)$ between the groups was the need for pharmacological reversai of residual paralysis. In a procedure with a mean duration of 45.6 minutes, and using isofiurane, all but one patient ( 95 per cent) in the atracurium group required neostigmine versus nine patients in the vecuronium group ( 45 per cent).
\end{abstract}

\section{Key words}

ANAESTHESIA: Outpatient: ANAESTHETICS, VOLATLL: isoflurane; NEUROMUSCULAR RELAXANTS: atracurium, vecuronium; RECOVERY: general anaesthesia; SURGERY: orthopacdic.

From the Department of Anesthesia, Academisch Medisch Centrum, Meibergdreef 9, 1105 AZ Amsterdam, The Netherlands.

Address correspondence to: Dr. Zuurmond.
Atracurium and vecuronium are non-depolarizing neuromuscular blocking agents of intermediale duration. Both drugs are appropriate for use in outpatient surgery, requiring adequate anaesthesia and rapid recovery without side effects. The influence of relaxants, antagonists and anticholinergic drugs on recovery and street fitness has only been studied by measuring the mechanical or electromyographic responses to stimulation. As the patient may show a complete teversal of the neuromuscular blockade by these measurements, recovery could be delayed by double vision or inability to focus or possible central effects, due to either the minimal residual effects of the relaxant and its metabolites, or the influence of antagonists and anticholinergic drugs, used in reversal.

Vecuronium is five times more potent than atracurium. ${ }^{1,2}$ This study was designed to compare recovery from general anaesthesia, using as the relaxant equipotent doses of atracurium $\left(0.5 \mathrm{mg} \cdot \mathrm{kg}^{-1}\right)$ or vecuronium bromide $\left(0.1 \mathrm{mg} \cdot \mathrm{kg}^{-1}\right)$ in day-case patients undergoing arthroscopy of the knee. Neostigmine and atropine were used if necessary for reversal of neuromuscular blockade.

\section{Methods}

Forty healthy patients aged $16-49$ years, ASA physical status class 1, scheduled for diagnostic arthroscopy of the knee under general anaesthesia participated in the study. This study was approved by the Medical Ethical Committee of the hospital, and all patients gave verbal informed consent. The patients were examined preoperatively. None were taking any medication likely to affect recovery from anaesthesia. After assessment, baseline preanaesthetic values of tests used to assess recovery were obtained. No premedication was given.

The patients were randomly allocated to two groups. Group $A(n=20)$ received atracurium $0.5 \mathrm{mg}^{\circ} \mathrm{kg}^{-1}$ and Group $B(n=20)$ vecuronium $0.1 \mathrm{mg} \cdot \mathrm{kg}^{-1}$ for tracheal intubation and profound muscle relaxation for testing of knee function and arthroscopy. General anaesthesia was achieved with preoxygenation, methohexitone $1 \mathrm{mg} \cdot \mathrm{kg}^{-1}$ IV and three per cent (inspired) isoflurane prior to intubation.

Anaesthesia was maintained with nitrous oxide 66 per 
cent in oxygen and 0.9 per cent (inspired) isoflurane, using a circle absorber system with a fresh gas flow rate of $3 \mathrm{~L} \cdot \min ^{-1}$. Patients were ventilated to maintain $\mathrm{FECO}_{2}$ between 4-5 vol per cent (measured by capnograph). At the end of surgery the inhalational anaesthesia was discontinued. This time was defined as the end of anaesthesia.

Neuromuscular function was monitored with the compound electromyogram (EMG) of the right hypothenar muscles in response to supramaximal train-of-four (TOF) stimuli every 20 seconds, delivered to the uinar nerve at the wrist, using a Datex Relaxograph ${ }^{\mathbb{E}}$ (Datex Instrumentarium Corp., Helsinki, Finland). This recorder compares the first twitch to the control (TI) and the fourth twitch to the first (TOF-ratio). It gives a digital display of these values as well as a continuous graphic printout on a chart recorder.

Following induction, the Datex Relaxograph ${ }^{\text {wa }}$ was calibrated prior to administration of the relaxant. Neuromuscular blockade was reversed at the end of anaesthesia when the TOF-ratio was less than 0.75 , the generally accepted measure of adequate clinical recovery of neuromuscular transmission, ${ }^{3}$ using appropriate doses of neostigmine and atropine. Utilizing a non-invasive blood pressure monitor (Dinamap ${ }^{*}$ Critikon, Inc, Tampa, FL, USA) and a continuous ECG, the heart rate, systolic and diastolic arterial blood pressures were recorded.

\section{Assessment of recovery}

Recovery from anaesthesia was assessed in a double-blind fashion by the same observer who was unaware of the anaesthetic technique, using the same methods as in previous studies. ${ }^{4,5}$

- The time elapsed from the end of anaesthesia until spontaneous eye opening.

- The time elapsed from eye opening until the patients were orientated and could answer the following questions:

What is your name? How old are you? Can you show me your right thumb? What day is it today? How much is $7 \times 8$ ?

- Measurement of ocular imbalance assessed by Maddox Wing test ${ }^{6}$ every 20 minutes. The interval between the end of anaesthesia and the time that the patient reached their preanaesthetic values was measured.

- A "p"-deletion test was performed 30,60 and 120 minutes after the end of anaesthesia, using a modified form of the test described by Dixon and Thomton ${ }^{7}$ : every patient received a text containing 140 p's and was asked to delete as many p's as possible without omissions in three minutes. The total number of $p$ 's deleted was measured.

- Clinical assessment of the patients during the recovery period with regard to level of arousal, the incidence of
TABLE I Sex ratio, age and weight of parients and duration

of aresthesia (mean \pm SD)

\begin{tabular}{lll}
\hline & $\begin{array}{l}\text { Group A } \\
\text { Arracurium } \\
n=20\end{array}$ & $\begin{array}{l}\text { Group B } \\
\text { Vecuronium } \\
n=20\end{array}$ \\
\hline Female/Male & $10 / 10$ & $10 / 10$ \\
Age (years) & $29.1 \pm 8.5$ & $28.0 \pm 6.3$ \\
Weight (kg) & $71.0 \pm 15.4$ & $72.4 \pm 12.5$ \\
Duration (min) & $45.6 \pm 11.9$ & $45.7 \pm 8.4$ \\
\hline
\end{tabular}

side effects and the need for antiemetic or analgesic drugs.

- Clinical assessment of the patient's opinion one month after anaesthesia.

Statistical analysis was performed using the unpaired Student's $t$ test for the major of group differences; the Chi-square test with the Yates' correction was used for the incidence of side effects and drugs given postoperatively. Comparing the scores of the p-deletion tests a repeated measures analysis of variance was performed followed by Student's $\mathrm{t}$ test for paired data. $\mathrm{P}<0.05$ was considered to be significant.

\section{Results}

Both groups of patients were comparable with respect to age, weight and sex (Table I). There was no significant difference in the duration of andesthesia. All patients underwent anaesthesia and arthroscopy without complications. Heart rate, systolic and diastolic arterial blood pressure varied with the depth of anaesthesia during induction and maintenance. Hypotension (more than 25 per cent decrease of mean arterial pressure related to preoperative values) did not occur. Heart rate did not exceed the range of $55-120$ beats $\cdot \mathrm{min}^{-1}$

\section{TABLE II Mean values \pm SD of indices of necovery}

\begin{tabular}{llll}
\hline & $\begin{array}{l}\text { Group A } \\
\text { Arracurium } \\
n=20\end{array}$ & $\begin{array}{l}\text { Group B } \\
\text { Vecuronitum } \\
t=20\end{array}$ & $p$ \\
\hline $\begin{array}{l}\text { Time to opening } \\
\text { eyes (min) }\end{array}$ & $9.2 \pm 2.7$ & $10.8 \pm 3.1$ & NS \\
$\begin{array}{l}\text { Time to giving } \\
\text { correct answers } \\
\text { to } 5 \text { questions } \\
\text { affer eye opening (min) }\end{array}$ & $2.6 \pm 2.2$ & $3.3 \pm 2.5$ & NS \\
$\begin{array}{l}\text { Time to recovery } \\
\text { of ocular imbal ance } \\
\text { (Maddox Wing) from } \\
\text { end of anaesthesia (min) }\end{array}$ & $131.1 \pm 29.8$ & $120.9 \pm 42.5$ & NS \\
\hline
\end{tabular}

(NS $=$ nol significant $)$. 
At the end of anaesthesia the mean TOF ratio's in group A (atracurium) and B (vecuronium) showed a significant difference $(p<0.01)$ being respectively $0.23 \pm 0.05$ and $0.57 \pm 0.07$. Ninetecn patients in group A required reversal versus nine patients in group $B(p<0.01)$. Nevertheless all patients left the operating theatre with a TOF-ratio greater than 0.75 , and with clinical evidence of return to normal neuromuscular function.

The time between the end of anaesthesia and eye opening, and the time to achieve correct verbal responses was the same in both groups (Table II).

There was also no difference between the groups in the time to recovery of ocular balance using Maddox Wing test. The range was 60 to 120 minutes.

The p-deletion scores reached their preanaesthetic values in both groups after 60 minutes and showed a similar pattern of recovery: the repeated measures analysis of variance showed no group effects, while after 30 minutes a time effect was seen in both groups, a significantly lower value than preoperatively (Table III). Clinical assessment of wakefulness in both groups was virtually identical, with all patients being completely awake by one hour postoperatively.

The incidence of side effects and the drugs given postoperatively are listed in Table IV.

The incidence of nausea and vomiting was equal in both groups (ten per cent). All patients were fit for discharge at the end of a recovery period of three hours.

One month after the procedure the patients were interviewed. All were satisfied with their anaesthetic and recovery. The mean time of full recovery, according to patients' opinions ("feeling back to normal") was $1 \frac{1}{2}$ day (range $1 \mathrm{~h}-7$ days) for both groups.

The surgeon was satisfied with the relaxation for testing the knee and operative conditions in all patients.

\section{Discussion}

The present study was performed to evaluate recovery from anaesthesia for outpatient arthroscopy comparing two different non-depolarizing relaxants of intermediate duration in a standardized anaesthetic technique: atracurium versus vecuronium. Succinylcholine can be used for these procedures but is associated with undesirable side-effects, including muscle pain. Neuromuscular function was assessed by the Datex Relaxograph ${ }^{\text {BD }}$ an electromyographic monitor, reported to be a reliable and accurate neuromuscular function monitor. ${ }^{8}$

The mean duration of anaesthesia was similar for both groups. Monitoring of relaxant effects revealed a significant $(p<0.01)$ difference between groups. At the end of anaesthesia the TOF-ratio in the atracurium group was lower than in the vecuronium group and a higher number
TABLE III Number of deleted letter $p$ 's (mean \pm SD)

\begin{tabular}{lll}
\hline $\begin{array}{l}\text { Number of deleted } \\
\text { tetter } p \text { in text }\end{array}$ & $\begin{array}{l}\text { Group } A \\
\text { Atracurium }\end{array}$ & $\begin{array}{l}\text { Group } B \\
\text { Vecuronirm }\end{array}$ \\
\hline $\begin{array}{l}\text { Preoperative } \\
30 \text { min after end } \\
\text { of anaesthesia }\end{array}$ & $58.3 \pm 12.7$ & $62.4 \pm 13.4$ \\
$\begin{array}{c}60 \text { min after end } \\
\text { of anaesthesia }\end{array}$ & $35.5 \pm 19.1 \dagger$ & $45.1 \pm 16.2^{*}$ \\
$\begin{array}{c}120 \text { min after end } \\
\text { of anaesthesia }\end{array}$ & $53.1 \pm 18.4$ & $58.6 \pm 14.2$ \\
\hline
\end{tabular}

Repeated measures analysis of variance: no group effects; however, a time effect present after 30 minutes. Student's $t$ test for paircd data was then performed comparing each patient's delected letter $p^{\prime} s$ with their own preanaesthetic values. ${ }^{*} p<0,01, t_{p}<0,001$.

( $p<0.01$ ) of patients needed pharmacological reversal of residual paralysis in Group A (95 versus 45 per cent in Group B). This suggests a longer duration of action of atracurium compared with vecuronium

These results are similar to previous studies indicating a quicker recovery from the effects of vecuronium than from equipotent doses of atracurium. ${ }^{1,9}$ However, in our study isoflurane was used as the inhalational anaesthetic. There are no reports comparing the potentiating effects of isoflurane on atracurium and vecuronium in adults, in the same study. Rupp et al. ${ }^{10-12}$ compared in separate studies the influence of volatile anaesthetics, including isoflurane, on the neuromuscular effects of either atracurium or vecuronium. They stated ${ }^{12}$ that the potency of vecuronium and atracurium in adults is affected identically (lower than 20 per cent) by the choice of the volatile anaestheric; however, to a lesser degree than tubucurarine or pancuronium.

Total recovery of neuromuscular transmission was achieved in all patients before leaving the operating room. Neostigmine, if used, reversed the ncuromuscular blockade adequately before the patients awakened.

As in previous studies, ${ }^{2.3}$ besides clinical assessment, a number of tests were performed before and after the

TABLE IV Incidence of side-effects and dngs given postoperatively (number of patients in each group)

\begin{tabular}{llll}
\hline & $\begin{array}{l}\text { Group A } \\
\text { Alracurium } \\
n=20\end{array}$ & $\begin{array}{l}\text { Group } \text { B } \\
\text { Vecuronium } \\
n=20\end{array}$ & \\
\hline Neostigmine (I mg) & & & \\
$\quad$ atropine (0.5 mg) IV & 19 & 9 & p $<0.01$ \\
Nausea andor vomiting & 2 & 2 & NS \\
Antiernetic drugs given & 2 & 2 & NS \\
Analgesic drugs given & 2 & 3 & NS \\
Dizziness, headache & 3 & 1 & NS \\
Not fit for discharge & 0 & 0 & NS \\
Awarezess & 0 & 0 & \\
\hline
\end{tabular}


procedure: a paper and pencil test ( $\mathrm{p}$-deletion test) to measure concentration, and measurement of the ocular imbalance by Maddox. Wing as described by Kortilla. ${ }^{13}$ Following anaesthesia which includes the administration of relaxants and, if needed, antagonists, patients may complain about double vision and/or inability to focus, even though neuromuscular measurements have shown recovery to be complete. On the other hand, patients are sometimes unaware of the strabismus which is present. Discharging such patients could be dangerous.

There were no significant differences in the results obtained from the recovery tests. The ocular balance, using the Maddox Wing, showed similar recovery in both groups in all cases within two hours. Thus, the effects of neostigmine and atropine, given to a greater number of patients in the atracurium group, were not detectable in the recovery period. Awareness was not reported by any of the patients.

In conclusion, atracurium and vecuronium provide satisfactory relaxation and rapid recovery in outpatient arthroscopy of the knee. The need for pharmacological reversal was an important difference. However, no significant differences were seen in the recovery tests.

\section{References}

1 Robertson EN, Booij LHDJ, Fragen RJ, Crul JF. Clinical comparison of atracurium and vecuronium (ORG NC 45). Br J Anacsth 1983; 55: 125-9.

2 Gramsted $L$, Lilleaasen $P$. Dose-response relation for attacurium, ORG NC45 and pancuronium. Br J Anaesth 1982; 54: 647-51.

3 Ali $H H, K i t z R J$. Evaluation of tecovery from nondepolatizing neuromuscular block, using a digital neuromusculir transmission analyzer. Preliminary teport. Anesth Analg 1973; 52: 740-5.

4 Zuurmond WWA, van Leeuwen $L$. Alfentanil $v$. isoflurane for outpatient arthroscopy. Acta Anaesthesiol Scand 1986; 30: $329-31$.

5 Zuurmond WWA, van Leeuwen L, Helmers JHJ. Recovery from propofol infusion as the main agent for outpatient arthroscopy. A comparison with isoflurane. Anaesthesia 1987; 42: 356-9.

6 Miller S.IH. Parsons diseases of the eye. 16th ed. Edin burgh: Churchill Livingstone, 1978; 492.

7 Dixon RA, Thornton JA. Tests of recovery from anaesthesia and sedation: intravenous diazepam in dentistry. $\mathrm{Br} J$ Anaesth 1973; 45: 207-15.

8 Carter JA, Arnold R, Yate PM, Flynn PJ. Assessment of the Datex relaxograph during anaesthesia and atracuriuminduced neuromuscular blockade. Br J Anaesth 1986; 58: 1447-52.
$9 O^{\prime}$ Hara DA, Fragen RJ, Shanks CA. Reappearance of the train-of-four after neuromuscular blockade induced with tubocurarine; vecuronium or atracurium. $\mathrm{Br} \mathrm{J}$ Anaesth 1986; 58: $1296-9$.

10 Rupp SM, Fahey MR, Miller RD. Neunomuscular and cardiovascular effects of atracurium during nitrous oxidcfentanyl and nitrous oxide-isoflurane anesthesit. Br J Anaesth 1983; 55: 67S-70S.

11 Rupp $S M$, Miller RD, Gencarelli $P J$. Vecuronium-induced neuromuscular blockade during enflurane, isoflurane, and halothane anesthesia in humans. Anesthesiology 1984; 60: 102-5.

12 Rupp SM, McChristian JW, Miller RD. Neuromuscular effects of atracurium during halothanc-nitrous oxide and cnflurane-nitrous oxide aresthesia in humans. Anesthesiology 1985; 63: 16-9.

13 Kortilla $K$. Recovery and driving after brief anaesthesia. Anaesthesist 1981; 30: 377-82.

\section{Résumé}

De l' atracurium $0.5 \mathrm{mg} \cdot \mathrm{kg}^{-1}$ et du vécuronium $0.1 \mathrm{mg} \cdot \mathrm{kg}^{-1}$ ont éré comparés comme agents relaxants musculaires chex des patients externes devant subir une arthroscopie du genou sous anesthêsie générale. Chez 40 patients non prémédiqués et divisés d' une façon randomisée en deux groupes l'anesthésie fut induite par le méthohexitone, atracurium (groupe A) ou vếchronium (groupe B), trois pour cent d'isofurane avant lintubation et 0.9 pour cent durant le maintien avec du protoxyde d'azore 66 pour cent oxygène. La fonction neuromusculaire a été enregistrée avec un Datex Relaxagraphe $\$$. La récupération a été évaluée par le temps que les patients ont pris pour ouvrir les veux afin de pouvoir répondre a cinq questions d'une façon adéquate, le temps de recouvrir l'équilibre oculaire (Maddox Wing test) et en comparant la performance pré et postopératoire avec un test du papier et du cravon (p-deletion test). Les tests de récupération n'ont pas démontré une différence significative entre les groupes. Trois heures plus tard tous les patients étaiemt prêts à prendre cangé. Les patients furent interviewés un mois après la procédure. Tous étaient satisfaits de leur anesthésie. "La récupération complète" a pris un jour et demi avec un écart de une heure d̀ sept jours. La seule différence significative $(p<0.01)$ entre les groupes étaient la nécessité de renverser pharmacologiquement la paralysie résiduelle. En urilisant l'isoflurane pour une procédure de durée moyenne de 45.6 minutes sous les patients sauf un (95 pour cent) du groupe atracurium ont nécessité de la néostigmine comparativement d neuf patients du groupe vécuronium (45 pour cent). 